\title{
Sub-Tenon's local anaesthesia: the effect of hyaluronidase
}

Steven A Rowley, Julia E Hale, Robin D Finlay

\begin{abstract}
Aims-A prospective, randomised, double blind study was used to investigate the effect of hyaluronidase on the quality of block achieved with sub-Tenon's local anaesthesia.

Methods-150 patients scheduled for elective cataract surgery were randomly allocated to either sub-Tenon's block with $3 \mathrm{ml}$ lignocaine $2 \%$ /adrenaline 1:200 000 alone or with the addition of $30 \mathrm{IU} / \mathrm{ml}$ of hyaluronidase. The blocks were assessed for degree of akinesia and reduction of eyelid movement, and also post-injection and postoperative pain scores.

Results-Akinesia and reduction of eyelid movement measured 10 minutes after injection were significantly better in the group with hyaluronidase added to the anaesthetic solution. Postoperative pain scores were not significantly different between the two groups but the postinjection pain score was greater (marginally significant) in the group with hyaluronidase added.

Conclusion-The addition of hyaluronidase significantly improves the quality of the motor blockade achieved with subTenon's local anaesthesia, but has no effect on the sensory blockade.

(Br f Ophthalmol 2000;84:435-436)
\end{abstract}

The single quadrant technique for sub-Tenon's local anaesthesia was popularised by Stevens ${ }^{1}$ in 1992 as a safe and effective method for ophthalmic anaesthesia, avoiding the risks of sharp needle techniques. Delivery of the local anaesthetic solution to the posterior sub-Tenon's space is followed by diffusion of the solution through Tenon's capsule and into the retrobulbar compartment where the anaesthetic exerts its effect. ${ }^{12}$ Hyaluronidase is an enzyme which catalyses the depolymerisation of hyaluronic acid to a tetrasaccharide and potentially increases diffusion of local anaesthetic through tissue planes. The use of hyaluronidase in retrobulbar anaesthesia has been shown to be of benefit ${ }^{34}$ in terms of speed of onset and quality of block, but the results with peribulbar techniques are more conflicting. ${ }^{5-7}$

To ascertain whether hyaluronidase had any effect on the quality of block with the sub-Tenon's technique, we conducted a randomised double blind study.

Correspondence to: Steven Rowley, Bristol Eye Hospital, Lower Maudlin Street, Bristol BS1 2LX

Accepted for publication 8 December 1999
Ethics committee approval for the study was patients scheduled to undergo elective cataract obtained and informed consent given by 150 surgery under local anaesthetic. Exclusion criteria were patients with learning difficulties, profound deafness, dementia, high anxiety scores, and those with a known adverse reaction to lignocaine or hyaluronidase.

Using random number tables, each of the patients was randomly allocated to one of two groups. The control group received $3 \mathrm{ml}$ lignocaine 2\%/adrenaline 1:200 000 (Xylocaine, Astra Pharmaceuticals Ltd) alone whereas the hyaluronidase group received $3 \mathrm{ml}$ lignocaine $2 \%$ /adrenaline $1: 200000$ with the addition of $30 \mathrm{IU} / \mathrm{ml}$ of hyaluronidase (Hyalase, CP Pharmaceuticals Ltd). The syringes were prepared at the start of the list by an independent assistant who took no further part in either administering or assessing the block. The ophthalmologist administering the block, the operative surgeon, and the nursing staff were unaware of the contents of the syringe. The blocks were performed by one of three ophthalmologists (SAR, JH, RDF) using the technique described by Stevens ${ }^{1}$ but using a Visitec 19 gauge sub-Tenon's cannula (5176) and only injecting $0.5 \mathrm{ml}$ of anaesthetic at the equator. A McIntyre intraocular pressure reducer was applied over the eye for 10 minutes.

Pain experienced during administration of block was measured immediately after injection and pain experienced peroperatively was measured immediately after surgery. The pain assessments were made by a trained ophthalmic theatre nurse without the investigator being present, using a visual pain analogue 10 $\mathrm{cm}$ in length ( 0 being no pain and 10 excruciating pain). Questions, phrasing, and intonation were as standardised as possible to avoid any bias. Akinesia and eyelid movement was assessed by the ophthalmologist administering the block 10 minutes after administration. The degree of akinesia was measured using a four point scale:

0 = complete movement remaining

$1=$ moderate movement

2 = slight movement $(<3 \mathrm{~mm}$ in any direction $)$ 3 = no movement.

Eyelid movement was assessed using a three point scale:

$0=$ normal movement

1 = reduced movement

2 = absent movement.

STATISTICAL METHODS

The power calculation was based upon the findings of a pilot study of pain scores in subTenon's block without hyaluronidase; a standard deviation of 3.0 was achieved. We considered the smallest clinically significant difference to be a reduction in pain score of 1.5 on the analogue scale. Choosing a 5\% significance 
Table 1 Patient demographics and proportions of blocks given by each investigator to the study

\begin{tabular}{llll}
\hline & $\begin{array}{l}\text { Hyaluronidase } \\
(n=76)\end{array}$ & $\begin{array}{l}\text { No hyaluronidase } \\
(n=74)\end{array}$ & \\
\hline $\begin{array}{l}\text { Age range (years) } \\
\text { Mean age }\end{array}$ & $37-96$ & $52-93$ & NS \\
$\begin{array}{l}\text { Male:female ratio } \\
\text { Blocks given by each }\end{array}$ & $22: 54$ & 36.51 & NS \\
$\quad$ investigator & & & \\
SAR & 57 & 48 & NS \\
JEH & 8 & 14 & \\
RDF & 11 & 12 & \\
\hline
\end{tabular}

Table 2 Akinesia, eyelid movement, and pain scores

\begin{tabular}{llll}
\hline & $\begin{array}{l}\text { Hyaluronidase } \\
(n=76)\end{array}$ & $\begin{array}{l}\text { No } \\
\text { hyaluronidase } \\
(n=74)\end{array}$ & \\
\hline Akinesia score & 2.32 & 1.43 & $\begin{array}{c}\text { Significant } \\
(\mathrm{p}<0.01)\end{array}$ \\
$\begin{array}{c}\text { Eyelid movement } \\
\text { score }\end{array}$ & 1.37 & 0.50 & $\begin{array}{c}\text { Significant } \\
(\mathrm{p}<0.01)\end{array}$ \\
$\begin{array}{c}\text { Post-injection } \\
\text { pain score }\end{array}$ & 2.26 & 1.95 & $\mathrm{NS}$ \\
$\begin{array}{c}\text { Postoperative } \\
\text { pain score }\end{array}$ & 1.04 & 1.03 & $\mathrm{NS}$ \\
\hline
\end{tabular}

level, Altman's nomogram gives a power of $90 \%$ with a sample number of 150 . Results were analysed using $\chi^{2}$ test, $\chi^{2}$ test for trend, $t$ test, or Mann-Whitney U test as appropriate.

\section{Results}

There were 76 patients in the "with hyaluronidase" group and 74 patients in the control group and the two groups were similar in terms of age, sex distribution, and also proportion of blocks administered by each investigator (Table 1 ).

The degree of akinesia and reduction of eyelid movement, measured 10 minutes after administration of the anaesthetic, was significantly better $(\mathrm{p}<0.01)$ in the hyaluronidase group (Table 2) and indeed complete akinesia was achieved in 40 cases in the hyaluronidase group compared with only 10 in the control group. The mean post-injection and postoperative pain scores were higher in the hyaluronidase group (Table 2) but these were not statistically significant.

There was one case of posterior capsule rupture requiring anterior vitrectomy in each group and in four cases (two in each group) a 7 mm PMMA intraocular lens was inserted into the sulcus because of incomplete capsulorrhexis. In none of these cases did the operating surgeon feel that the complication was due to the quality of the block.

\section{Discussion}

Although the use of topical anaesthesia alone is becoming more widespread in cataract surgery, there are patients for whom topical anaesthesia is not appropriate, perhaps because of poor patient cooperation, and where iris manipulation is required. In these cases, sub-Tenon's local anaesthesia provides a safe and effective block avoiding the risks of sharp needle techniques.

This study has shown that at 10 minutes after injection, the group with $30 \mathrm{IU} / \mathrm{ml}$ of hyaluronidase added to the anaesthetic solution had significantly better akinesia and reduced eyelid movement compared with those who did not. There was no improvement in sensory blockade with the addition of hyaluronidase but in both groups the quality of the block was excellent. This supports the findings of a recent study by Guise and Laurent ${ }^{8}$ who showed significantly better akinesia after 9 minutes in the "with hyaluronidase" group compared with the control group. When they compared the quality of block at 13 minutes, however, they found no significant difference between the two groups. During a busy cataract list with average operating time of 15-20 minutes, this improvement in rate of onset of akinesia is clearly advantageous in terms of list efficiency.

We used $30 \mathrm{IU} / \mathrm{ml}$ of hyaluronidase as it reflected our day to day practice, did not deviate too far from the manufacturer's recommended $15 \mathrm{IU} / \mathrm{ml}$, and was a similar concentration to those used in previous peribulbar studies. ${ }^{59}$ Our use of adrenaline in the anaesthetic solution again reflected our current practice and the potential risks of adrenaline in anaesthetic solutions are by no means proved..$^{10-12}$

In conclusion, hyaluronidase has a beneficial effect in improving the quality of motor blockade achieved with sub-Tenon's local anaesthesia but has no effect on the sensory blockade.

The authors would like to thank Lyn Church and Sue Sampson for the pain score assessments and Gordon Taylor (University of Bath) for his advice with the statistical analysis.

1 Stevens JD. A new local anaesthesia technique for cataract extraction by one quadrant sub-Tenon's infiltration. $\mathrm{Br} \mathcal{F}$ Ophthalmol 1992;76:670-4.

2 Stevens JD. The technique of sub-Tenon'sanaesthesia Video f Cataract Refract Surg 1996;12:4.

3 Abelson MB, Mandel E, Paradis A, et al. The effect of hyaluronidase on akinesia during cataract surgery. Ophthalmic Surg 1989;20:325-6.

4 Nicoll JM, Treuren B, Acharya PA, et al. Retrobulbar Nicoll JM, Treuren B, Acharya PA, et al. Retrobulbar
anaesthesia: the role of hyaluronidase. Anaesth Analg 1986; anaesthesia: the role of hyaluronidase. Anaesth Analg 1986; 65:1324-8

5 Prosser DP, Rodney GE, Mian T, et al. Re-evaluation of hyaluronidase in peribulbar anaesthesia. Br $\mathcal{F}$ Ophthalmol 1996;80:827-30.

6 Crawford M, Kerr WJ. The effect of hyaluronidase on peribulbar block. Anaesthesia 1994;49:907-8.

7 Bowman RJC, Newman DK, Richardson EC, et al. Is hyaluronidase helpful for peribulbar anaesthesia? Eye 1997;11:385-8.

8 Guise P, Laurent S. Sub-Tenon's block: the effect of hyaluronidase on speed of onset and block quality. Anaesth Intensive Care 1999;27:179-81.

9 Sarvela J, Nikki P. Hyaluronidase improves regional ophthalmic anaesthesia with etidocaine. Can $\mathcal{f}$ Anaesth 1992;39:920-4.

10 Hulbert MF, Yang YC, Pennefather PM. Pulsatile ocular blood flow and intraocular pressure during retrobulbar injection of lignocaine: influence of additives. I Glaucoma 998;7:413-16.

11 Jay WM, Aziz MZ, Green K. The effect of retrobulbar epinephrine injection on ocular and optic nerve blood flow. Curr Eye Res 1985;4:55-8.

12 Jay WM, Aziz MZ, Green K. Further studies on the effect of retrobulbar epinephrine injection on ocular and optic nerve blood flow. Curr Eye Res 1986;5:63-7. 